\title{
Spectrum of Thyroid Lesions in A Tertiary Care Hospital using Bethesda System for Reporting Thyroid Cytopathology
}

\author{
Mallikarjun A Pattanashetti ${ }^{*}$, Ranjit P Kangle ${ }^{2}$ and Hema B Bannur ${ }^{2}$ \\ 'Department of Pathology, S. Nijalingappa Medical College, Bagalkot, Karnataka, India \\ ${ }^{2}$ Department of Pathology, KLE University’s Jawaharlal Nehru Medical College, Belagavi, Karnataka, India
}

\section{ABSTRACT}

Background: Thyroid Fine Needle Aspiration (FNA) has been widely used as a first line investigation to assess thyroid nodules, as it is rapid, cost effective, safe and reliable. To bring uniformity and standardization in thyroid cytology reporting, "The Bethesda System for Reporting Thyroid Cytopathology" (TBSRTC) was introduced and it is gaining acceptance. This study has been undertaken to evaluate the reproducibility using TBSRTC system while reporting thyroid FNACs and to find out the utility of Bethesda system after correlating with the histopathology.

Methods: A retrospective study was conducted in which 173 cases of thyroid aspirates were reclassified according to TBSRTC in to six categories by cytologist.

Results: A total of 173 thyroid lesions were analysed. Category wise distribution of aspirates was Non diagnostic (ND) 9 (5.20\%), Benign (BN) $145(83.81 \%)$, Follicular neoplasm (FN) $9(5.20 \%)$, Follicular lesion of uncertain significance (FLUS) Nil, suspicious of malignancy(SM) $1(0.57 \%)$ and malignant category $9(5.20 \%)$. Age and sex wise distribution was interpreted. Thyroid diseases were more prevalent in women and most common age group affected was 3rd to 4th decade. Out of 164 lesions which were satisfactory for evaluation,120 $(73.17 \%)$ were simple goitre, $15(9.14 \%)$ were of thyroiditis, $6(3.65 \%)$ were toxic goitre, $4(2.43 \%)$ were thyroid cysts \& $19(11.57 \%)$ were neoplasms of which benign included $1(0.6 \%)$ Hurthle cell neoplasm and $8(4.87 \%)$ follicular neoplasm. Malignant lesions were $8(4.87 \%)$ papillary carcinoma, $1(0.6 \%)$ anaplastic carcinoma and $1(0.6 \%)$ medullary carcinoma.

Conclusions: It was observed that standardized nomenclature of the Bethesda system has brought much needed clarity in thyroid FNAC reporting. Along with malignant category, the FLUS, FN and SM categories carry higher malignancy risk.

Keywords: Thyroid FNAC; Bethesda System;

\section{Introduction}

Thyroid nodule is a common clinical condition and nearly 85 to $90 \%$ of them are benign lesions. ${ }^{[1,2]}$ Thyroid FNA has been widely used as a firstline investigation to assess thyroid nodules, as it is rapid, cost effective, safe and reliable. ${ }^{[3]}$ It is important that cytology report is unambiguous and clinically useful. It has been observed that thyroid FNAC smears terminologies vary significantly from one laboratory to other, sometimes from one cytologist to other in the same institution. This is creating confusion in some cases and has become an obstacle in sharing information amongst different institutions. ${ }^{[4,5]}$ This issue of terminology related to thyroid cytology was addressed at National Cancer Institute (NCI) which hosted "NCI thyroid FNA state of the science conference" which led to the formation of "The Bethesda System for Reporting Thyroid Cytopathology" (TBSRTC). ${ }^{[6]}$ The TBSRTC system is presently being widely used in US and several European Countries, and in India also it is gaining acceptance. This study has been undertaken to evaluate the reproducibility using TBSRTC system while reporting thyroid FNACs and to find out the utility of Bethesda system as there is lack of such data in this region.

\section{Materials and Methods}

Details of all the thyroid FNAC cases done from Jan 2009 to November 2014 in a tertiary care hospital were retrieved from archives of cytology section. Experienced cytologist with experience in cytology reporting and self learned the different aspects of TBRTC, reviewed the slides. All the clinical details and available radiological and thyroid function test results which were noted down in the original cytology request forms were provided to cytologist. The FNA smears were reclassified in a double blinded fashion into six categories as per TBSRTC.

The Six Categories are as below ${ }^{[7]}$

a. Non diagnostic (ND); Smears were considered as nondiagnostic when a thyroid FNA sample failed to fulfill the recommended criteria for adequacy which 
are presence of a minimum of six groups of well visualized follicular cells, with at least ten cells per group, preferably on a single slide, absence of colloid or only blood.

b. Benign (BN); Lesions were classified into this category if the smears showed features suggestive of colloid nodule, multinodular goiter, thyroiditis, as well as if the aspirate showed benign follicular cells only.

c. Follicular lesion of undetermined significance (FLUS); smears that contain cells with architectural and/or nuclear atypia that is not sufficient to be classified as suspicious for a follicular neoplasm or suspicious for a malignancy.

d. Follicular neoplasm (FN)/Suspicious for follicular neoplasm(SFN); Lesions were classified into this category if they were having high follicular cellularity with predominant microfollicle formations, scant colloid. Lesions exhibiting Hurthle cells predominantly were also included.

e. Suspicious for malignancy(SM); Smears in this category were mainly cellular with crowded cell groups exhibiting nuclear and cytoplasmic pleomorphism with some occasional single atypical cells. In the context of suspicious papillary carcinoma rare presence of nuclear enlargement, grooves, overlapping and/or pseudoinclusions along with thick colloid were considered suspicious. f. Malignant (MGT); Lesions were classified into this category if they were frankly malignant with type specification. The spectrum of all the thyroid lesions was classified as per the above six categories.

\section{Result}

A total of 173 thyroid lesions were analysed and categorized as per TBSRTC. Category wise distribution of aspirates was Non diagnostic (ND) 9 (5.20\%), Benign (BN) 145 (83.81 \%), Follicular neoplasm (FN) 9 (5.20\%), Follicular lesion of uncertain significance (FLUS) Nil, Suspicious of malignancy (SM) $1(0.57 \%)$ and Malignant category $9(5.20 \%)$ (Table 1$)$.

The various thyroid lesions in all the categories are described in Table 2 . The female to male ratio in our study was $3.5: 1$. The youngest patient was 11 year female child with simple colloid goitre. The oldest patient was 80 years male patient with papillary carcinoma. Most common age group affected with thyroid lesions was $3^{\text {rd }}$ to $4^{\text {th }}$ decade and most common thyroid lesion was simple colloid goitre which was most commonly seen in $3^{\text {rd }}$ to $4^{\text {th }}$ decade. Least common age group affected was 71-80 years. Most common lesion in $7^{\text {th }}$ to $8^{\text {th }}$ decade was colloid goitre with cystic change as shown in Table 3. Most common thyroid malignancy was Papillary carcinoma seen most commonly in $6^{\text {th }}$ to $7^{\text {th }}$ decade. Most common Inflammatory thyroiditis was Hashimoto's thyroiditis. The most common thyroid lesion in Pediatric age group was simple colloid goitre.

Table 1: Distribution of cases as per TBSRTC.

\begin{tabular}{|r|l|r|}
\hline \multicolumn{1}{|c|}{ Bethesda Diagnostic category } & Total \\
\hline I & Nondiagnostic or unsatisfactory (ND) & $9(5.20 \%)$ \\
\hline II & Benign (BN) & $145(83.81 \%)$ \\
\hline III & Atypia of undetermined significance (AUS) or Follicular lesion of undetermined significance(FLUS) & 0 \\
\hline IV & Follicular neoplasm or Suspicious for follicular neoplasm(FN /SFN) & $9(5.20 \%)$ \\
\hline V & Suspicious for malignancy (SM) & $1(0.57 \%)$ \\
\hline VI & Malignant (M) & $9(5.20 \%)$ \\
\hline & Total & 173 \\
\hline
\end{tabular}

Table 2: Distribution of cases as per TBSRTC

\begin{tabular}{|c|c|c|}
\hline LESIONS & TBSRTC Category & Total \\
\hline NONDIAGNOSTIC OR UNSATISFACTORY & 1 & $9(5.20 \%)$ \\
\hline BENIGN & \multirow{10}{*}{ II } & $145(83.81 \%)$ \\
\hline Simple Colloid goitre & & 79 \\
\hline Colloid goitre with cystic change & & 30 \\
\hline Thyroid cyst & & 4 \\
\hline Toxic goitre & & 6 \\
\hline Multinodular goitre & & 11 \\
\hline Acute thyroiditis & & 1 \\
\hline Granulomatous thyroiditis & & 2 \\
\hline Lymphocytic thyroiditis & & 4 \\
\hline Hashimoto's thyroiditis & & 8 \\
\hline
\end{tabular}




\begin{tabular}{|c|c|c|}
\hline LESIONS & TBSRTC Category & Total \\
\hline $\begin{array}{l}\text { ATYPIA OF UNDETERMINED SIGNIFICANCE OR FOLLICULAR LESION OF } \\
\text { UNDETERMINED SIGNIFICANCE }\end{array}$ & III & 0 \\
\hline $\begin{array}{l}\text { FOLLICULAR NEOPLASM OR SUSPICIOUS FOR A FOLLICULAR } \\
\text { NEOPLASM }\end{array}$ & \multirow{3}{*}{ IV } & $9(5.20 \%)$ \\
\hline Follicular neoplasm & & 8 \\
\hline Hurthle cell neoplasm & & 1 \\
\hline SUSPICIOUS FOR MALIGNANCY & $\mathrm{V}$ & $1(0.57 \%)$ \\
\hline MALIGNANT & \multirow{4}{*}{ VI } & $9(5.20 \%)$ \\
\hline Papillary Carcinoma & & 7 \\
\hline Anaplastic carcinoma & & 1 \\
\hline Medullary carcinoma & & 1 \\
\hline Total & & 173 \\
\hline
\end{tabular}

Table 3: Age wise distribution of thyroid lesions.

\begin{tabular}{|c|c|c|c|c|c|c|c|c|c|}
\hline \multirow{2}{*}{ Lesion } & \multicolumn{9}{|c|}{ Age in years } \\
\hline & $<10$ & $11-20$ & $21-30$ & $31-40$ & $41-50$ & $51-60$ & $61-70$ & $71-80$ & TOTAL \\
\hline $\begin{array}{l}\text { NONDIAGNOSTIC OR } \\
\text { UNSATISFACTORY }\end{array}$ & - & - & 1 & 2 & 3 & 2 & 1 & - & 9 \\
\hline \multicolumn{10}{|l|}{ BENIGN } \\
\hline Simple Colloid goitre & - & 4 & 16 & 24 & 15 & 14 & 6 & - & 79 \\
\hline Colloid goite with cystic change & - & - & 4 & 9 & 7 & 5 & 3 & 2 & 30 \\
\hline Thyroid cyst & - & - & 1 & 1 & - & & 1 & 1 & 4 \\
\hline Toxic Goitre & - & - & 1 & 1 & 2 & 2 & & - & 6 \\
\hline Multinodular goitre & - & - & 2 & 1 & 4 & 3 & 1 & - & 11 \\
\hline Acute thyroiditis & - & - & - & 1 & - & - & - & - & 1 \\
\hline Granulomatous thyroiditis & - & 1 & - & 1 & - & - & - & - & 2 \\
\hline Lymphocytic thyroiditis & - & - & 2 & 2 & - & - & - & - & 4 \\
\hline Hashimoto's thyroiditis & - & - & 1 & 2 & 2 & 2 & 1 & - & 8 \\
\hline AUS / FLUS & - & - & - & - & - & - & - & - & 0 \\
\hline \multicolumn{10}{|l|}{ FN / SFN } \\
\hline Hurthle cell neoplasm & - & - & - & 1 & - & - & - & - & 1 \\
\hline Follicular neoplasm & - & - & 1 & 4 & 1 & 1 & 1 & - & 8 \\
\hline SUSPICIOUS FOR MALIGNANCY & - & - & - & & - & 1 & - & - & 1 \\
\hline \multicolumn{10}{|l|}{ MALIGNANT } \\
\hline Papillary Carcinoma & - & - & 1 & 1 & 1 & - & 3 & 1 & 7 \\
\hline Anaplastic carcinoma & - & - & - & & 1 & - & - & - & 1 \\
\hline Medullary carcinoma & - & - & - & 1 & & - & - & - & 1 \\
\hline Total & 0 & 5 & 30 & 51 & 36 & 30 & 17 & 4 & 173 \\
\hline
\end{tabular}




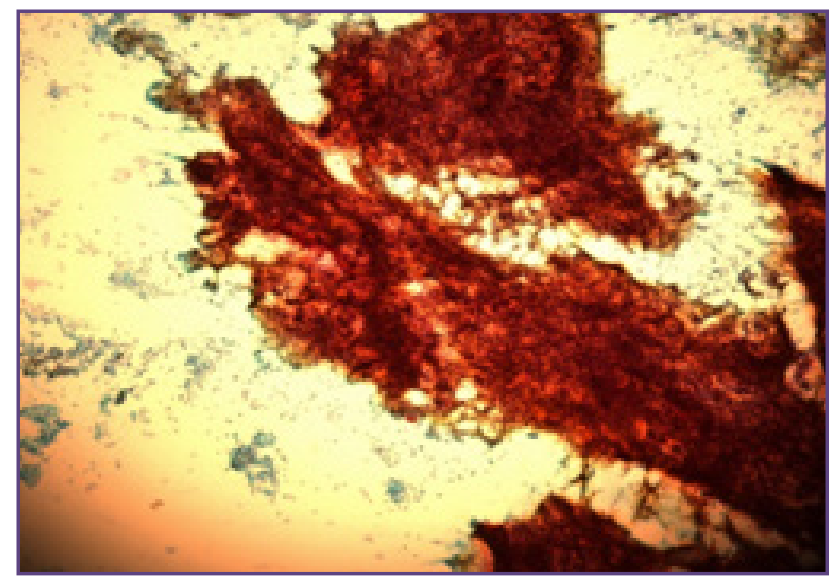

Fig. 1: Smear shows abundant follicular epithelial cells in macrofollicles against background of thick and thin colloid suggestive of colloid goitre ( PAP stain - X 10).

\section{Discussion}

Fine needle aspiration cytology is considered standard diagnostic test for the diagnosis of thyroid lesions. There is a lack of uniformity which is a big hindrance in interpreting the reports of thyroid FNA. Institutional, personalized and descriptive terminologies without proper categorization is leading to confusion in the minds of treating physicians. TBSRTC system was introduced after the Bethesda meeting of cytopathologists, endocrinologists, surgical pathologists, radiologists and surgeons to put in place, a universal reporting system through which cytologists and physicians could understand each other and could help in predicting the prognosis by estimating the malignant potential of the individual category. ${ }^{[7,8,9]}$ An attempt was made in the present study, to reclassify the 173 cases according to the new proposed six tier diagnostic classification system in reporting thyroid FNA results as Non diagnostic (ND) 9 (5.20\%), Benign (BN) 145 (83.81\%), Follicular neoplasm (FN) $9(5.20 \%)$,Follicular lesion of uncertain significance (FLUS) Nil, Suspicious of malignancy (SM) $1(0.57 \%)$ and malignant category 9(5.20). TBSRTC also assists in calculating the malignancy risk for eash category which is essential for treatment decision. Benign category was maximum in our study similar to the other studies (Table

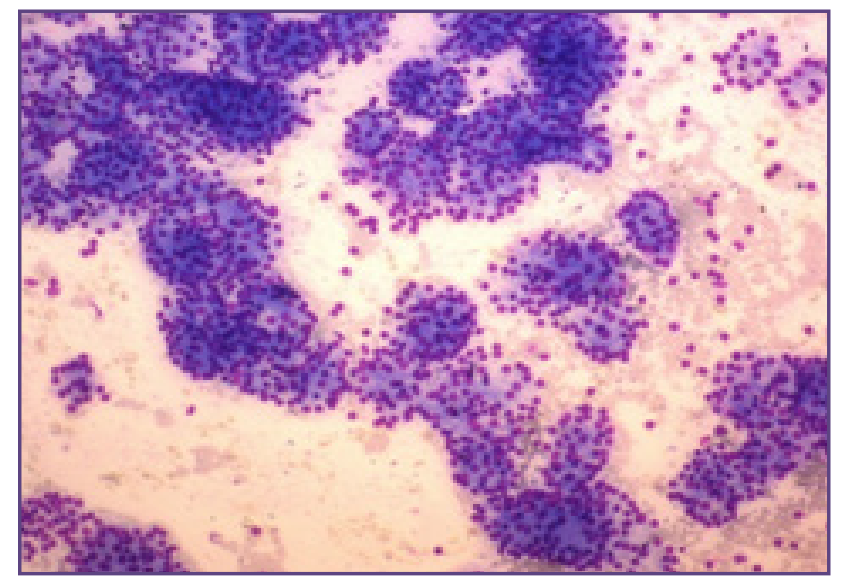

Fig. 2: Smear shows cellular smears showing numerous microfollicles with scanty colloid in the background. (Giemsa stain - X 10).

4). The various benign lesions (Class II) found in our study were Simple colloid goitre, Colloid goitre with cystic change, Thyroid cyst, Toxic goitre, Multinodular goitre, Acute thyroiditis, Granulomatous thyroiditis, Lymphocytic thyroiditis and Hashimoto's thyroiditis. The class IV included Follicular neoplasm and Hurthle cell neoplasm. The malignant class VI included Papillary carcinoma, Anaplastic carcinoma and Medullary carcinoma However, percentage of $\mathrm{BN}$ is much higher accounting for $83 \%$ in our study may be because of the fact that along with the referral cases, our hospital caters to the needs of many direct hospital visitors without reference. Like in general population, benign lesions were maximum in our set up. Percentage of FLUS category was less as per TBSRT recommendations. Our study was compared with studies by Parikh et al ${ }^{[10]}$, Uma et al ${ }^{[11]}$ and Bhatta et al. ${ }^{[12]}$ It was found that most were benign lesions similar to all other studies. However our study had similar Non-diagnostic (ND) smears as study by Uma et al. The number of follicular neoplasms/ Suspicious for follicular neoplasms seen in our study is $5.2 \%$ which is higher as compared all other studies which reported around $3.2 \%$. The malignant cases in our study is $5.2 \%$ which varied widely from $2.5 \%$ to $11.1 \%$ in various other studies.

Table 4: Comparison to other studies

\begin{tabular}{|l|c|c|c|c|}
\hline Lesions & Parikh et al & Uma et al & Bhatta et al & Our study \\
\hline Non diagnostic / Unsatisfactory & 19 & 22 & - & 9 \\
\hline Benign & 207 & 381 & 77 & 145 \\
\hline FN / SFN & 8 & 14 & 3 & 9 \\
\hline Suspicious for malignancy & - & - & - & 1 \\
\hline Malignancy & 6 & 17 & 10 & 9 \\
\hline Total & $\mathbf{2 4 0}$ & $\mathbf{4 3 4}$ & $\mathbf{9 0}$ & $\mathbf{1 7 3}$ \\
\hline
\end{tabular}




\section{Conclusion}

Fine needle aspiration cytology is standard diagnostic test for the diagnosis of thyroid lesions with a high diagnostic yield, accuracy, sensitivity \& specificity. Fine needle aspiration cytology is a cost effective procedure that provides specific diagnosis rapidly with minimum complications. It was observed that standardized nomenclature of the Bethesda system is more systematic and brought much needed clarity in thyroid FNAC reporting. Along with malignant category, the FLUS, FN and SM categories carry higher malignancy risk. Close follow up of the patients and surgical intervention option has to be considered in FLUS, FN and SM categories. However, a prospective study with large number of cases for cytohistopathological correlation may be needed to improve our understanding of these TBSRTC categories.

\section{Acknowledgement}

The authors would like to thank the patients for their assistance in the study. W also thank Department of Pathology and Department of Surgery, Jawaharlal Nehru Medical College, Belagavi for their support.

\section{References}

1. Sakorafas GH. Thyroid nodules; interpretation and importance of fine needle aspiration (FNA) for the clinician - Practical considerations. Surg Oncol 2010;19:130-9.

2. Redman R, Yoder BJ, Massoll NA. Perceptions of diagnostic terminology and cytopathologic reporting of fineneedle aspiration biopsies of thyroid nodules: a survey of clinicians and pathologists. Thyroid.2006;16:1003-8.

3. Baqqa PK, Mahajan NC. Fine needle aspiration cytology of thyroid swelling: how useful and accurate is it? Indian Journal of Cancer.2010;47:437-42.
4. Cibas ES. Fine needle aspiration in the workup of thyroid nodules. Otolaryngol Clin North Am 2010;43:257-71.

5. Park JH, Kim HK, Kang SW, Jeong JJ, Nam KH, Chung WY, et al. Second opinion in thyroid fine needle aspiration biopsy by the Bethesda System. Endocr J.2012;59:205-12.

6. Baloch ZW, Li Volsi VA, Asa SL, Rosai J, Merino MJ, Randolph G, et al. Diagnostic terminology and morphologic criteria for cytologic diagnosis of thyroid lesions: A synopsis of the national cancer institute thyroid fine needle aspiration state of the science conference. Diagn Cytopathol 2008;36:425-37.

7. Cibas ES, Ali SZ. The Bethesda system for reporting thyroid cytopathology. Am J Clin Pathol 2009;132:658-65.

8. Richmond BK, O’Brien BA, Mangano W, Thompson S, Kemper S. The impact of implementation of the bethesda system for reporting thyroid cytopathology on the surgical treatment of thyroid nodules. Am Surg 2012;78:706-10.

9. Layfield LJ, Morton MJ, Cramer HM, Hirschowitz S.Implications of the proposed thyroid fine needle aspiration category of "follicular lesion of undetermined significance": A five year multi institutional analysis.Diagn Cytopathol 2009;37:710-4.

10. Parikh UR, Goswami H.M., Shah AM., Mehta N.P, Gonsai R.N. Fine Needle Aspiration Cytology (FNAC) Study of Thyroid Lesions (Study of 240 Cases) Gujarat medical Journal; 2012;67(2):25-30.

11. Bhatta S, Makaju R, Mohammad . Role of fine needle aspiration cytology in the diagnosis of thyroid lesions; Journal of Pathology of Nepal.2012;2:186-8.

12. Uma Handa, Sukant garg, Harsh Mohan, Nitin Nagarkar .Role of fine needle aspiration cytology in diagnosis and management of thyroid lesions: A study on 434 patients.J Cytol.2008;25(1):13-8.

*Corresponding author:

Dr. Mallikarjun .A .Pattanashetti, Plot No 295 , RS No 183, 3rd Main, 2nd Stage, Hanuman nagar, Belagavi - 590001, Karnataka, India

Phone: +919739462156

Email: mallikarjun2030@gmail.com

Financial or other Competing Interests: None.

Date of Submission : 09.02.2017

Date of Acceptance : 13.03.2017 